\title{
ORGANIZAÇÃO CURRICULAR NA EDUCAÇÃO INFANTIL: UMA QUESTÃO DE GESTÃO ESCOLAR
}

Leandra Fernandes do Nascimento ${ }^{1}$

Maria Marina Dias Cavalcante ${ }^{2}$

\section{INTRODUÇÃO}

Freire (2000) afirmava que pensar certo, descobrir a razão de ser dos fatos e aprofundar os conhecimentos que a prática proporciona não são um privilégio de alguns, mas um direito que todos têm, numa sociedade revolucionária.

Assim, pode-se compreender que aprofundar os estudos, deve ser essencial para o docente em especial, pois, investigar o que está a sua volta é o dinamismo do seu trabalho e precisa de dedicação para por em prática.

Face ao exposto, surgiram as seguintes perguntas que norteiam essa investigação: Qual a compreensão dos professores e dos coordenadores pedagógicos sobre o processo de organização curricular na Educação Infantil? O que é realmente organização curricular? Como se pode saber se o que é ensinado faz parte do currículo? Desse modo propõe-se discorrer sobre estes assuntos, a fim de esclarecer o que significa currículo na Educação Infantil.

Realizou-se a pesquisa com abordagem Qualitativa a fim de se colher informações do corpo docente e com base nela propor intervenções e estratégias que despertem o interesse dos professores para a busca de conhecimentos.

Traz-se a tona a sua importância e a necessidade dos professores conhecerem sua função e a necessidade da escola de uma atenção especial à organização curricular. O professor jamais deixa de aprender e ensinar, pois permanece todo o tempo construindo o conhecimento e nunca será tarde para se aprender.

1 Doutoranda em Educação - PPGE/UECE - leandrafn@yahoo.com.br

2 Professora Efetiva da Universidade Estadual do Ceará - UECE e - PPGE/UECE - maria.marina@uece.br 
Junto com a coordenação pedagógica os docentes têm a oportunidade de entender o Projeto que presidem as atividades educativas escolares e elaborarem suas intenções e suas ações adequadas para a faixa etária em que atuam.

\section{ORGANIZAÇÃO CURRICULAR: LIMITES E POSSIBILIDADES NA EDUCAÇÃO INFANTIL}

Em latim currículo significa: movimento progressivo ou carreira, constituindo uma totalidade que devia não apenas ser seguido mas também acabado, em primeira mão está relacionado com a carreira que se vai seguir. Nas escolas o termo está relacionado às disciplinas a serem estudadas.

Arroyo (2011), declara que o currículo muitas vezes não coincide com a realidade social que os cursos de formação e de educação básica estão distante das verdades que os mestres e alunos vivenciam. É por esta razão que muitas vezes nas escolas em reuniões com professores, é declarado que não se pode incluir mais nada em suas aulas porque devem cumprir todo o conteúdo que está proposto no livro, caso não cumpra, não estará seguindo o currículo conforme o que foi programado no início do ano.

Com sorte pode-se entender que é necessário uma reflexão, para um melhor entendimento e na definição da teoria e das práticas escolares. O discurso educacional, mais especificamente no campo do currículo, estava basicamente centrado em responder a pergunta “como?”, ou seja, qual a melhor forma de "transmitir conhecimento" ou de criar comportamentos de ajustamento aos grupos sociais. Michael Apple, então, propõe que a educação e o currículo deveriam propor outras perguntas: “O quê?” e "para quem?” (APPLE, 2011, p.30).

Assim, se transmitiria conhecimentos com responsabilidades, longe do conceito do senso comum, e a formação do professor ficar em evidência.

Conforme Arroyo (2011), o que está acontecendo é uma mudança de identidade profissional, e esta mudança também afeta nossa identidade pessoal e dependendo do foco é forçado a aprender muitas vezes o que não se ensina nos cursos de formação. Assim o professor se sente despreparado no cotidiano das salas de aula e no convívio com os alunos.

Para Apple (2011), currículo são roteiros da ação na sala de aula, que funcionam como script, ditam exatamente o que fazer, como fazer e quando fazer. Para Popkewitz (2011) estudioso no assunto, o currículo tem efeitos sociais e subjetivos, pois, é um conhecimento que organiza as percepções (pensar), as formas de responder ao mundo (agir) e as concepções do eu (sentir). 
A Educação Infantil, primeira etapa da Educação Básica, tem como finalidade o desenvolvimento integral da criança até seis anos de idade, em aspectos físicos, psicológico, intelectual e social, complementando a ação da família e da comunidade. (Art. 29 Lei 9394/96).

A escola tem a função de educar e de transmitir o saber, a Educação Infantil se modificado e ampliado suas funções. Segundo Medel (2012),

O currículo, na visão multicultural, deve trabalhar em prol da formação das identidades abertas à pluralidade cultural, desafiadora de preconceitos em uma perspectiva de educação para a cidadania, para a paz, para a ética, nas relações interpessoais, para a crítica as desigualdades sociais e culturais.

Com tudo isso, sabe-se que a tarefa essencial da Educação Infantil é cuidar e recrear. O Referencial Curricular para a Educação Infantil (RCNEI, 1998) mostra que existem temas importantes a serem trabalhados sendo,

\footnotetext{
Substituição da explanação pelo desenvolvimento de projetos que nasçam da curiosidade e dos questionamentos feitos pela própria criança; explorar os valores procedimentais e de reafirmar a importância de sua prática para a riqueza da conveniência social; utilizar-se de múltiplas linguagens como expressão das diferentes inteligências das crianças; explorar jogos; despertar da consciência de que todo ser humano é sempre agente transformador do mundo.
}

Antunes (2012), ainda destaca que a Educação Infantil estará desenvolvendo pelo menos três elementos cruciais na formação da criança. A descoberta das coisas nas quais pensa, a identificação das coisas com as quais a criança pensa e a compreensão do espaço no qual o pensamento é desenvolvido. O currículo na Educação Infantil tem sua importância, pois trás para nós sua diversidade, instabilidade e a ação de todos em sua transformação.

Entre as décadas de 1960 a 1970 foram revelados outros níveis de currículo: formal, real e oculto. Eles informam o quanto o aluno aprendeu ou deixou de aprender.

\section{COORDENAÇÃO PEDAGÓGICA}


É necessário para o coordenador pedagógico ter compreensão de que o currículo formal é um conjunto de indicações oriundas da Lei de Diretrizes e Bases (LDB) e com isto deverá junto com os docentes construir o Projeto Político Pedagógico (PPP) a fim de traçar o perfil do aluno que a escola pretende formar.

Segundo Mate (2009), a função de coordenador pedagógico é nova e requer capacitação e empenho, pois o desafio é grande e exigirá principalmente que:

\begin{abstract}
A troca de experiência passe a ter um significado especial, em que a escuta do outro também adquire um sentido de aprendizado. Enfim, o falar e ouvir sobre as experiências passam a fazer parte constitutiva dos projetos em (re)construção, de modo que a busca, o contato e o dialogo em diferentes referenciais teóricos brotam do desejo de compreensão e de respostas para as perguntas e as angustias geradas no espaço de trabalho.
\end{abstract}

O coordenador pedagógico deve ser um professor experiente que irá contribuir para que o trabalho dos outros professores aconteça de forma organizada e efetiva a ponto de promover o desenvolvimento dos alunos, além de cuidar também do desenvolvimento do professor.

É o coordenador pedagógico que deve contribuir para que o ambiente seja democrático, em busca de novos conhecimentos por parte da comunidade escolar, além de incentivar os professores a participarem de estudos em busca de novas informações e a vivência de novas realidades. O seu trabalho só será possível se ele desenvolver outras competências como nos relata Assis (2009),

\begin{abstract}
Ampliar sua escuta, modificando sua fala quando a leitura da realidade assim pedir. Ter uma consciência coletiva, a ponto de flexibilizar os planejamentos para que eles sejam construídos partindo do olhar do professor e do olhar coletivo. Ter a capacidade de perceber o espaço da relação e da troca de aprendizagem com a equipe. Perceber o que está acontecendo com o professor e seu grupo de alunos. Perceber quais conhecimentos necessários ele precisa ter para auxiliar o professor (ASSIS, 2009, p. 76).
\end{abstract}

Fica bem claro que o coordenador pedagógico deva ser um professor e que tenha conhecimento da rotina de uma sala de aula, para compreender o mecanismo que cercam a sua atuação.

Organizar as atividades a serem realizadas em sala de aula requer cuidados e conhecimentos, para que a rotina não seja mecânica e repetitiva, pois essa faixa etária de 0 a 6 anos exige metodologias específicas e variadas, por isso, a rotina deve ser bem planejada com atividades adequadas, 
contextualizadas e significativas. Para isto o educador deve: organizar o ambiente (espaço físico adequado), o uso do tempo, a seleção e as propostas de atividades e por último a seleção e a oferta de materiais.

É necessário nos dias atuais que se observe e se conheça bem os documentos que ajudam na organização de propostas pedagógicas na Educação Infantil, quanto a fundamentos, procedimentos, elaboração, planejamento, avaliação e também a legislação estadual e municipal, bem como as normas do respectivo sistema educacional.

Antunes (2012), orienta que as crianças não aprendem somente após os seis anos, mesmo antes desta idade elas são capazes de aprender, por isso a tarefa da Educação Infantil é muito importante. O Referencial Curricular Nacional para a Educação Infantil (RCNEI,1998) dá um destaque para que as propostas pedagógicas busquem a interação entre diversas áreas do conhecimento. É necessário que integrem os aspectos físicos, emocionais, afetivos, cognitivo, linguísticos e sociais de toda criança.

A partir do planejamento, o educador, junto com a coordenação pedagógica devem desenvolver as experiências de aprendizagem. Cabe ao professor ser flexível, realizando ajustes necessários para essas experiências de aprendizagens.

De acordo com as propostas das Diretrizes Gerais do MEC, as escolas deverão oferecer condições adequadas de desenvolvimento físico, emocional, cognitivo e social da criança e promover a ampliação de suas experiências e conhecimento, estimulando seu interesse pelo processo de transformação da natureza e pela convivência em sociedade.

Outro fator importante, apontado por Antunes (2012) é que não se separa a ideia do brincar do aprender, dessa forma, brincando e jogando, a criança constrói conceitos, explora sua criatividade, inventa e reinventa, transformando a realidade de seu entorno, de suas emoções e do seu corpo.

Ao professor cabe buscar estratégias que desenvolvam a mente infantil, desperte a curiosidade da criança a expressar seus sentimentos. É preciso que o educador tenha conhecimento de brincadeiras, músicas infantis, histórias, jogos e outras atividades, pois, são alguns dos recursos que poderá usar para desenvolveram diferentes experiências pedagógicas.

Durante a avaliação o docente deverá refletir acerca de sua prática pedagógica, observando suas mediações, analisando as estratégias utilizadas, se o grupo participou bem, se o trabalho foi facilitado com as suas orientações, se os recursos foram adequados e suficientes para o número de alunos e se o tempo foi apto para a realização das atividades. 
De acordo com a Lei de Diretrizes e Bases da Educação Nacional (LDB) deve prevalecer o uso de processos avaliativos de instrumentos e meios que possam diagnosticar as dificuldades da criança e gerar tomadas de decisões para superá-las. A orientação dada é que esta avaliação poderá ser feita através de registros bimestrais e comparados com o anterior, devendo ser guardada à individualidade do aluno.

\section{PRINCIPAIS DOCUMENTOS LEGAIS SOBRE EDUCAÇÃO INFANTIL}

Segundo o Referencial Curricular Nacional para a Educação Infantil (RCNEI -1998) a criança, como todo ser humano, é um sujeito social e histórico e faz parte de uma organização familiar que está inscrita em uma sociedade, com uma determinada cultura, em um determinado momento histórico. É profundamente marcada pelo meio social em que se desenvolve, mas também deixa marca.

A criança como sujeito histórico vem se destacando na sociedade, nas ciências e no âmbito educacional, de maneira legal através do Estatuto da Infância e Adolescência (ECA) - afirma que,

\footnotetext{
O reconhecimento de seu direito a educação é um dos espaços promissores. A presença da infância na sociedade era reconhecida, ora como objeto de cuidados, de proteção, de assistência, ora como incomodo, como um ser pré-humano submetido aos instintos, irracional, in-fans, não falante porque ainda não pensamente: na minoridade intelectual, moral, humana. Um ser humano em potencial, logo sem direitos (ARROYO, 2011, p.179).
}

É dever do Estado garantir a oferta de Educação Infantil público, gratuito e de qualidade, sem requisito de seleção.

A Lei de Diretrizes e Bases da Educação (LDBEN 4.024/1961), no Art. $2^{\circ}$ - nos informa que a educação é um direito de todos e será dada no lar e na escola, devendo ser assegurada pelo poder público e iniciativa privada a fim de ministrarem o ensino em todos os graus na forma da lei em vigor.

No capítulo I, Art. 23- Ainda a Lei de Diretrizes e Bases da Educação Nacional (LDB) a educação pré-primária destinava-se aos menores de até sete anos, e era ministrada em escolas maternais ou jardins de infância. O ensino primário tem por fim o desenvolvimento do raciocínio e das atividades de expressão da criança e a sua integração no meio físico e social, e será administrado, no mínimo em quatro séries anuais. 
É importante que os pais percebam o desenvolvimento da criança. Segundo Antunes (2012) " a Educação Infantil é muito importante para a compreensão do espaço no qual o pensamento é desenvolvido".

A LDB (LDBEN 5.692/1971), traz no seu Art.17 que o ensino de $1^{\circ}$ Grau destina-se a formação da criança e do pré-adolescente, variando em conteúdo e métodos segundo as fases de desenvolvimentos dos alunos.

A Lei $n^{\circ} 12.796$, de 4 de abril de 2013, altera a Lei ${ }^{\circ}$ 9.394, de 20 de dezembro de 1996, que estabelece as diretrizes e bases da educação nacional, para dispor sobre a formação dos profissionais da educação e dar outras providencias,

\begin{abstract}
A formação de docentes para atuar na educação básica far-se-á em nível superior, em curso de licenciatura, de graduação plena, em universidades e institutos superiores de educação, admitida, como formação mínima para o exercício do magistério na educação infantil e nos 5 (cinco) primeiros anos do ensino fundamental, a oferecida em nível médio na modalidade normal.
\end{abstract}

Antes da mudança da constituição, o Ensino Fundamental era a única fase escolar obrigatória no Brasil. Depois da aprovação da emenda, o ensino passou a ser obrigatório dos 4 aos 17 anos, incluindo a Pré-escola, o Ensino Fundamental e Médio.

A Educação Infantil somente foi inserida na Lei Nacional em 1988, quando foi colocada como parte integrante da Constituição Federal de 1988 e consolidado pela Lei de Diretrizes e Bases da Educação Nacional (LDBEN 9.394/96). Em 1990, com o Estatuto da criança e do adolescente (ECA, Lei Federal 8069/90), entre os direitos está o atendimento em creches e Pré-escolas para as crianças até os seis anos de idade.

As Diretrizes Gerais do MEC para a Educação Infantil estão centrados nos seguintes eixos:

A Educação Infantil é a primeira etapa da Educação Básica e destina-se à criança de zero a seis anos de idade. Não constitui obrigatoriedade, mas representa um direito a que o Estado tem obrigação de atender;

As instituições que oferecem a Educação Infantil, integrantes dos Sistemas de Ensino, são as creches e pré-escolas, dividindo-se a clientela entre elas pelo critério exclusivo da faixa etária;

A Educação Infantil é oferecida para, em complementação à ação da família, proporcionar condições adequadas de desenvolvimento físico, emocional, cognitivo e social da criança e promover a ampliação de suas experiências e conhecimentos, estimulando seu interesse pelo processo de transformação da natureza e pela convivência em sociedade; 
As ações de educação, na creche e na pré-escola, devem ser complementadas pelas de saúde e assistência, realizadas de forma articulada com os setores competentes;

O currículo da Educação Infantil deve levar em conta, na sua concepção e administração, o grau do desenvolvimento da criança, a diversidade social e cultural das populações infantis e os conhecimentos que se pretendam universalizar;

Os profissionais de Educação Infantil devem ser formados em cursos de nível médio ou superior, que contemplem conteúdos específicos relativos a essa etapa da educação;

As crianças com necessidades especiais devem, sempre que possível, ser atendidas na rede regular de creches e Pré-escola. (ANTUNES, 2012, p.14).

Dentre os eixos das Diretrizes Gerais do MEC para Educação Infantil, deve- se tornar claro a necessidade de se conhecer o grau do desenvolvimento da criança, a sua diversidade cultural e social para que não se tenha a ideia de que crianças da Educação Infantil só aprendem quando atingir a idade de 6 anos.

A curiosidade deve ser o eixo que levará a criança a descobrir o mundo que está a sua volta. Não importa se os temas trazidos pela curiosidade infantil foram "os dinossauros", "as profissões" ou "um dia na fazenda", o que cabe resaltar é que o tema escolhido deve suscitar questões que envolvam diferentes áreas do saber- da expressão vocabular ao domínio das questões numéricas, da identidade do ontem e do agora à contextualização do tema ao encontro e ao corpo do aluno (ANTUNES, 2012, p.45).

Conhecer o que diz as Diretrizes Gerais do MEC para a educação Infantil é de fundamental importância e necessária ao grupo docente, pois encontrará nelas apoio para exercer suas funções com competência e segurança, acrescentando aprendizagens específicas de acordo com a faixa etária desse segmento educacional.

\section{FORMAÇÃO DOCENTE E ORGANIZAÇÃO CURRICULAR: FACES DA MESMA MOEDA}

A formação do professor é de fundamental importância para que se compreenda como ele pensa, constrói estratégias e como realiza seu trabalho prático escolar. Chama a atenção de que a aprendizagem é uma relação de poder, mesmo assim deve-se ver que a pedagogia compreende visões de mundo e ações práticas, a fim de produzir e reproduzir este mundo. (POPKEWITZ, 2011). 
Em 1996, a Lei de Diretrizes e Bases (LDB) determinou em seu Artigo 62, que para atuar na Educação Básica é essencial que o professor possua nível superior e que no prazo de dez anos somente professores habilitados em nível superior seriam admitidos. (ANTUNES, 2012, p.17).

Com isto, aconteceu uma corrida em busca de formação, mas o resultado não foi o que se esperava. A falta de formação específica, ainda revela algo impressionante como informa Antunes (2012),

\begin{abstract}
Mesmo entre os educadores que cursaram Ensino Superior, ainda se percebe a falta de formação específica para a Educação Infantil Por esse motivo, em 1999 institui-se o Curso Normal Superior que, organizado pelos Institutos de educação para formar docentes em Educação Infantil e Ensino Fundamental, busca preparar especialistas para o trabalho escolar com a infância (ANTUNES, 2012, p.17).
\end{abstract}

Saber o que ensinar, quando ensinar, como ensinar e como avaliar, deve ser pontos importantes e conhecidos de qualquer docente e que fazem parte de um currículo eficiente.

O professor é responsável tanto pelo seu conhecimento, quanto pelo conhecimento do seu aluno. É preciso dedicação para que o professor veja seu trabalho valorizado como se deve.

Segundo Cerisara (2002), a educação é composta na sua maioria por mulheres em uma profissão que guarda traço de ambiguidade entre a função materna e a função docente.

Encontram-se muitas pessoas em sala de aula que não tem nenhuma vocação para a profissão e mesmo assim estão lá sem as devidas condições.

Fica claro o que dizem as leis, mas então por que não se cumpre o que dizem? Com uma formação superior inadequada, entende-se que as propostas pedagógicas, as leis que asseguram a Educação Infantil e o currículo sejam ignorados por muitos profissionais, já que a proposta deste seguimento mostra um extenso leque de atividades que se precisam realizar.

O Referencial Curricular Nacional para a Educação Infantil (RCNEI, 1998), afirma que há uma necessidade de formação abrangente e unificadora para profissionais tanto de creches como de pré-escola e de uma reestruturação dos quadros de carreira que leve em consideração os conhecimentos já acumulados no exercício profissional, como possibilite a atualização profissional.

A formação superior visa à especialização de profissionais para a Educação Infantil. Ela não é a solução para educação, mas sim uns dos caminhos a ser percorridos para se chegar ao menos ao que se pretende alcançar em nossas escolas. 
O Referencial Curricular Nacional para Educação Infantil relata que o professor precisa ter uma competência polivalente. Ser polivalente significa que o professor sabe trabalhar com conteúdos de naturezas diversas que abrangem desde cuidados básicos essenciais até conhecimentos específicos provenientes das diversas áreas de conhecimento.

Este caráter polivalente demanda, por sua vez, uma formação bastante ampla do profissional que deve se tornar, ele também, um aprendiz, refletindo constantemente sobre sua prática, debatendo com seus pares, dialogando com as famílias e a comunidade e buscando informações necessárias para o trabalho que desenvolve. São instrumentos essenciais para a reflexão sobre a prática direta com as crianças a observação, o registro, o planejamento e a avaliação. (RCNEI, 1998.p.41).

Quanto ao currículo a LDBEN n 4.024/1961 informa,

Título V. Art.12 - Os sistemas de ensino atenderão a variedade dos cursos, a flexibilidade dos currículos e a articulação dos diversos graus e ramos.

Art. 20 - Na organização do ensino primário e médio a lei federal ou estadual atenderá:

a variedade de métodos de ensino e formas de atividade escolar, tendo em vista as peculiaridades da região e de grupos sociais.

ao estímulo de experiências pedagógicas com o fim de aperfeiçoar os processos educativos.

Conforme nos mostra a lei, entendemos que o professor deverá elaborar atividades, para serem executadas conforme os interesses de cada grupo e do lugar onde vivem. A vivência de cada dia despertará o interesse pelos estudos e a novas descobertas.

Art. 4 (1971) - Os currículos de ensino de $1^{\text {o e }} 2^{\circ}$ graus terão um núcleo comum obrigatório em âmbito nacional, e uma parte diversificada para atender conforme as necessidades e possibilidades concretas, as peculiaridades locais dos planos dos estabelecimentos e as diferenças individuais dos alunos.

§ Observar-se-ão as seguintes prescrições na definição dos conteúdos curriculares:

O Conselho Federal de Educação fixará para cada grau as matérias relativas ao núcleo comum, definindo-lhes os objetivos e a amplitude.

Os conselhos de Educação relacionarão, para os respectivos sistemas de ensino, as matérias dentro às quais poderá cada estabelecimento escolher as que devam construir a parte diversificada.

Os decretos, leis e resoluções revelam que muitas coisas precisam ser ajustadas e melhoradas. 


\section{PROCEDIMENTOS METODOLÓGICOS}

Durante alguns meses foram feitas observações na escola XY, localizada na cidade de Fortaleza/CE, com participação na rotina escolar, situação em que se buscou compreender melhor o pensamento dos professores em relação ao assunto.

Fez-se uma abordagem através de uma investigação qualitativa onde se analisou o que foi dito pelos professores na entrevista sob a visão dos teóricos mencionados com o intuito de compreender melhor a organização curricular na educação infantil.

Através de estudos de textos dos autores Ayres (2012), Cerisara (2002), Freire (2002), Antunes (2012) e outros estudiosos da educação, além de documentos legais sobre a Educação Infantil, fundamentou-se a pesquisa com a intenção de atingir o objetivo de uma reflexão sobre a compreensão de professores e coordenadores pedagógicos em relação ao processo de organização do currículo na Educação Infantil.

Para chegar ao objetivo deste trabalho, selecionou-se dez professores de uma escola da rede privada, estabelecida na cidade de Fortaleza, foram considerados para a entrevista aqueles professores que tinham mais tempo de trabalho na escola. Durante o estágio da Gestão Escolar observou-se que a prática de alguns professores os denunciava por falta de experiências e conhecimentos apropriados para exercer sua profissão. A pesquisa foi feita com o objetivo de fazer uma reflexão e ter a compreensão sobre a organização curricular na Educação Infantil, os depoimentos só comprovaram o que fora observado. Tratou-se do conceito de currículo, sua função e importância para a Educação Infantil, fase considerada importantíssima para o desenvolvimento geral da criança.

Por esta razão, a entrevista foi à estratégia escolhida para identificar o conhecimento dos professores sobre a organização curricular, a fim de conhecer através de suas práticas, a rotina da escola e compreender o desenvolvimento do currículo dentro da entidade. Os dados coletados serviram de base para a conclusão desta pesquisa

Para Minayo (1994), a entrevista favorece a obtenção de informações através da fala individual, a qual revela condições estruturais, sistemas de valores, normas e símbolos e transmite o entendimento de determinados grupos. 
Utilizou-se a entrevista semi-estruturada, na qual o informante tem a possibilidade de discorrer sobre suas experiências, a partir do foco principal proposto pelo pesquisador; ao mesmo tempo que permite respostas livres e espontâneas do informante.

A autorização para realizar a entrevista foi concedida pela Direção da Escola. Os professores foram devidamente esclarecidos sobre: o objetivo da pesquisa, o procedimento e da utilização das informações dos professores em caráter sigiloso do estudo.

A entrevista utilizou um roteiro de perguntas abertas em forma de diálogo e transcorreu com algumas intervenções com o intuito de estimular os professores a continuarem falando e de maneira individual, onde poucos professores precisaram de estímulos para se expressar. Os professores usaram uma linguagem simples.

\section{Roteiro das perguntas:}

a) O que é currículo para você?

b) Como a escola estabelece seu currículo?

c) Qual a importância do currículo na elaboração do seu planejamento?

d) Como você compreende a função do currículo na educação Infantil?

e) Quais as necessidades técnicas para a execução do trabalho na Educação Infantil?

\section{ANÁLISES DOS DADOS}

\section{P1 - O que é currículo?}

Dos dez professores entrevistados, quatro declararam que currículo são as disciplinas ou matérias que a escola oferece aos alunos. Antunes (2012) deixa claro que isto é uma preocupação constante dos professores e nos declara, que basta interrogar a um professor sobre o que fará em sala de aula e sua resposta, invariavelmente aponta para um tema do currículo: "Descobrimento do Brasil”, "leis da genética", “máximo divisor comum” e assim por diante (ANTUNES: 2012, p. 44).

Os professores responderam como compreendem o termo currículo, esquecendo que na verdade o currículo é um guia que vai orientar os professores em suas ações em sala de aula. As respostas mostram que os professores desconhecem o verdadeiro significado da palavra currículo.

Saviani (1998) destaca que a visão do currículo está acompanhada pelas ideias de ordem e disciplina. 
Quando surgiu o termo currículo estava voltado para a carreira que o aluno deveria seguir. $\mathrm{O}$ termo currículo tem uma evolução de registro de vida do aluno para a expressão latina "currículo vitae" significando carreira (SAVIANI; 1998 p. 21).

Para outro grupo de professores, currículo está relacionado a matérias e conteúdos, como histórico escolar do aluno e ainda pode-se encontrar outras funções para o currículo como: instrumento político, sucesso para o crescimento escolar e as práticas escolares. Isto prova que o termo currículo é desconhecido dos professores.

De acordo com as diretrizes do MEC para a Educação Infantil, o currículo deve levar em conta, na sua concepção e administração, o grau do desenvolvimento da criança, a diversidade social e cultural das populações infantis e os conhecimentos que se pretendem universalizar.

\section{P2 - Como a escola estabelece o seu currículo?}

Segundo as Diretrizes Gerais do MEC a Educação Infantil é oferecida para complementação à ação da família, proporcionando condições adequadas de desenvolvimento físico, emocional, cognitivo e social da criança e promovendo a ampliação de suas experiências e conhecimentos, além de estimular seu interesse pelo processo de transformação da natureza e pela convivência em sociedade (ANTUNES, 2012, p.14).

O currículo deve seguir as diretrizes gerais do MEC, estando voltadas para regiões específicas de acordo com a necessidade de cada região.

De acordo com as diretrizes curriculares nacionais todo processo da proposta pedagógica deve ser elaborada coletivamente, além de contemplar os princípios éticos, políticos e estéticos, as instituições de Educação Infantil devem oferecer condições favoráveis para que as crianças gozem de seus direitos, tomando sobre si responsabilidade na educação das crianças, ampliando saberes e promovendo igualdade de oportunidades educacionais entre as crianças, deixando de lado todas as diferenças que de alguma forma ou outra impediria o desenvolvimento da criança.

Para Ayres (2012) é necessário que haja desenvolvimento de todos os aspectos físicos, emocionais, afetivos e cognitivos-linguísticos da criança. Pode-se então observar que o currículo deve contemplar os objetivos gerais e específicos que se quer atingir para que este desenvolvimento aconteça.

Alguns professores fugiam do conteúdo da pergunta, e ofereceram respostas rápidas, curtas e sem fundamentos, caracterizam o senso comum na formação do docente. 


\title{
P3 - Qual a importância do currículo na elaboração do seu planejamento?
}

Neste bloco as respostas foram muito parecidas. Segundo Apple (2011) o currículo são roteiros da ação em sala de aula, ditam exatamente o que fazer, como fazer e quando fazer.

A importância do currículo é percebida pelos professores através de suas respostas, e de acordo com as diretrizes curriculares as instituições de Educação Infantil devem se preocupar em garantir que se cumpram os objetivos destacados na proposta pedagógica.

Ainda é destacada a articulação de conhecimentos e aprendizagens de diferentes linguagens como também o direito à proteção, à saúde, à liberdade, à confiança, ao respeito, à dignidade, à brincadeira, à convivência e a interação com outras crianças.

É através do currículo, segundo Medel (2012), que se pode trabalhar em todas as perspectivas:

O currículo pode apresentar fases folclóricas, perspectivas em que mostre a influencia de diferentes povos na formação da cultura (árabes, africanos, e outros povos), a perspectiva multicultural crítica de desafios e preconceitos, pode ainda em momentos diferentes apresentar a diversidade dentro da diversidade.

Assim pode-se perceber a importância do currículo na elaboração do planejamento, pois as diretrizes que são dadas são vastas e amplas e não se pode ignorar sua existência.

\section{P4 - Como você compreende a função do currículo na Educação Infantil?}

Diante das respostas dadas pelos professores e conhecendo um pouco mais das diretrizes curriculares nacionais, observa-se que o currículo tem como função dar diretrizes para nortear as interações e brincadeiras.

É compreendido que:

\begin{abstract}
Brincando a criança desenvolve a imaginação, fundamenta afetos, explora habilidades, na medida em que assume múltiplos papéis, fecunda competências cognitivas e interativas. É brincando que a criança elabora conflitos e ansiedades, demonstrando ativamente sofrimentos e angústias que não se sabe como explicitar (ANTUNES, 2012, p.31).
\end{abstract}

É importante que todos percebam a importância do currículo, pois através dele o professor precisa criar condições favoráveis a fim de executar em sala de aula atividades que possibilitem descobertas, a experiência e a criatividade. 
Assim estará garantindo que as crianças tenham conhecimentos de si e do mundo por meios de experiências, mergulhando em diferentes linguagens, possibilitando as diversas práticas de vida, ampliando sua confiança e participação em várias atividades. Com isto estará incentivando ainda a curiosidade, o conhecimento em relação ao mundo físico e social, ao tempo e a natureza.

Se o currículo é bem conhecido, saberiam que para ensinar na educação infantil o professor precisa está preparado e munido de conhecimento tanto teórico como empírico.

\section{P5 - Quais as necessidades técnicas para e execução do trabalho infantil?}

A maior parte dos professores destacaram os diversos recursos que podem ser utilizados na escola. Uma parte reduzida do grupo não fez a relação destes recursos. Porém será preciso que todos conheçam as necessidades que podem encontrar no seu trabalho junto à Educação Infantil na instituição que trabalham e propõe-se um estudo para possam adquirirem conhecimentos adequados para usar ao executar o planejamento em sala de aula.

Segundo Medel (2012) a escola deve estar preparada com um ambiente educativo para potencializar as aprendizagens decorrentes desta faixa etária escolar.

Espaços, materiais e equipamentos das instituições infantis destinam-se prioritariamente as crianças, eles são construídos e organizados para atender as necessidades de saúde, alimentação, proteção, descanso, interação, conforto, higiene e aconchego das crianças matriculadas. Também são destinados espaços diferenciados para as atividades das crianças, para a dos profissionais, para os serviços de apoio e para o acolhimento das famílias ou responsáveis. Este grupo reconheceu bem os recursos que podem usar no seu trabalho.

Para Ayres (2012) os professores da Educação devem valorizar esta fase da vida da criança e buscar soluções assegurando um direcionamento satisfatório e dar conta das necessidades que emergem quando se tem objetivo de oferecer o trabalho mais adequado ao desenvolvimento global infantil.

As interações que se desenvolvem em sala de aula devem ser planejadas para que nestes momentos aconteçam aprendizagens significativas, e acima de tudo as crianças tenham prazer em está na escola. 


\section{CONSIDERAÇÕES FINAIS}

A Educação Infantil é uma fase importante para o desenvolvimento global da criança. Conhecer as leis, a estrutura da organização curricular e entender para que serve o currículo, como organizar o tempo e as atividades adequadas para a educação infantil são mecanismos que dão conta que o trabalho como educador não se limita somente a estar numa sala de aula, sem ter o preparo devido para exercer a profissão docente. Exige renúncia, dedicação e coragem para realizar um fazer um bom trabalho.

Chegou-se ao entendimento que a organização curricular vai além das disciplinas a serem ensinadas, mostra que se andou muito tempo na escuridão, mas agora se compreende que todo mecanismo que envolve a educação está dentro da organização curricular.

Nem tudo o que se aprendeu foi de maneira correta, eficaz e para sempre. Não se admite mais hoje em dia, que o profissional da educação seja um ser sem compromisso com o seu trabalho, omisso nas suas ações, e que permaneça naquilo que faz há muitos anos. É Preciso saber que hoje, a informação chega mesmo sem ir atrás dela, precisa-se aproveitar as oportunidades para se aprender a cada momento. Portanto, é preciso produzir, criar e recriar. É preciso desenvolver a ciência e a técnica. Não se pode parar no primeiro obstáculo que se encontra. (FREIRE, 2000).

Ao avaliar os relatos dos professores quanto ao assunto em estudo, fica evidente que é em parte desconhecido pelos mesmos. É necessário que eles estudem mais para que o seu trabalho tenha qualidade e seja valorizado pelas pessoas que estão precisando de sua ajuda.

O que se pode relatar é que o professor-gestor é responsável pelo desenvolvimento de muitos educandos e que a formação continuada dos professores é uma bandeira que se levanta no trabalho do professor, incentivando-o a leitura e a busca de conhecimento.

Entende-se que o professor precisa transformar o seu mundo (sala de aula), através da busca de novos conhecimentos para fazer bem feito aquilo que se propôs a fazer.

O profissional da educação infantil deverá considerar o que seja útil para a aprendizagem dos alunos e como favorecer as interações produtivas neste sentido, promovendo didáticas que possibilitem reais aprendizagens, motivando os alunos para que participem e deem suas contribuições também durante a aula.

As atividades promovidas pelo docente deverão está adequadas e devem ser bem articuladas a fim de que possam alcançar os objetivos estabelecidos, além de criar um ambiente favorável a aprendizagem. O docente poderá refletir sobre o desempenho de cada aluno no dia e também se 
autoavaliar, refletindo se suas ações foram ou não favoráveis à aprendizagem de seu aluno. Um docente bem preparado para exercer sua profissão alcançará êxito em suas ações.

Assim, compreende-se que a organização curricular nada mais é do que o conjunto de atividades que podem direcionar as tomadas de decisões e com isso realizar os procedimentos necessários para uma boa aprendizagem.

Acredita-se que este estudo possa contribuir de maneira significativa, ajudando assim, os novos amantes da educação. Vale destacar, que é um assunto que precisa ser mais trabalhado, pois quase não se tem trabalhos acadêmicos sobre a organização curricular na Educação Infantil, criando uma perspectiva que será de grande importância para a academia e para o vasto campo de estudo.

\section{REFERÊNCIAS}

ARROYO, Miguel G. Currículo, território em disputa. Petrópolis, RJ: Vozes, 2011.

ASSIS, Silvana Lúcia Chaves. Guia do coordenador: educação infantil. Belo Horizonte: Editora Educacional, 2009.

AYRES, Sônia Nunes. Educação Infantil: teorias e práticas para uma proposta pedagógica. Petrópolis, RJ; Vozes 2012.

BRASIL. MEC. Secretaria de Educação Básica. Diretrizes curriculares nacionais para educação infantil. Brasília: MEC, SEB, 2010. 1997.126p

Secretaria de Educação Fundamental. Introdução aos parâmetros curriculares nacionais. Brasília: MEC/SEF,

LDBEN (1961). Lei 4024, de 20/12/1961. Dispõe acerca das diretrizes e Bases da Educação Nacional. Brasília: MEC, 1961.

LDBEN (1971). Lei 5692, de 11/08/1971. Dispõe acerca das diretrizes e Bases da Educação Nacional. Brasília: MEC, 1971

LDBEN 9394, de 20/12/1996. Dispõe acerca das diretrizes e Bases da Educação Nacional. Brasília: MEC, 1996. 1998.

Secretaria de Educação Básica. Parâmetros Nacionais de Qualificação para Educação Infantil. Brasília - DF.

Secretaria de Educação Fundamental. Referencial Curricular Nacional para a Educação Infantil. Brasília: MEC/SEF,1998. 3v.

BRASIL. Lei $\mathbf{n}^{\circ} \mathbf{1 2 . 7 9 6}$, de abril de 2013. Altera a Lei no 9.394, de 20 de dezembro de 1996, que estabelece as diretrizes e bases da educação nacional, para dispor sobre a formação dos profissionais da educação e dar outras providências. Disponível em: </http://www.planalto.gov.br/ccivil_03/ato2011-2014/2013/lei/112796.htm> Acesso em: 02 de janeiro de 2017.

BRUNO, Eliane Bambini Gorgueira; CHRISTOV, Luiza Helena da Silva (org) O coordenador pedagógico e a educação continuada. São Paulo: Edições Loyola, 2009.

CERISARA, Ana Beatriz. Professoras de educação infantil: entre o feminino e o profissional. São Paulo: Cortez, 2000. 
COLL, César. Psicologia e Currículo: Uma aproximação psicopedagógica à elaboração do currículo escolar. Barcelona: Editora Ática, 1987.

FREIRE, Paulo. A importância do ato de ler: em três artigos que se completam. São Paulo; Cortez, 2000.

MEDEL, Cássia Ravena Mulin de A. Educação Infantil: da construção do ambiente às práticas pedagógicas. Petrópolis, RJ: Vozes, 2012.

MINAYO, Maria Cecília de Souza. (Org.) O desafio de conhecimento. Pesquisa qualitativa em saúde. 11 ed. São Paulo: Hucitec, 2008.

NUNES, Ana Cristina da Silva. Saberes e competências: diferentes desafios em cada etapa. Revista Nova Escola. Dossiê coordenador pedagógico- SP, junho/julho: 2011.

OLIVEIRA-FORMOZINHO, Julia. Pedagogia(s) da Infância: dialogando com o passado construindo o futuro. In.: Júlia Oliveira- Formosinho, Tizuko Morchida Kishimoto, Mônica Appezzato Pinazza (org) Pedagogia(s) da Infância. Porto Alegre: Artmed, 2007.

POPKEWITZ, T. S. História do currículo, regulação social e poder. In: SILVA, T. T. da (Org.). O sujeito da educação: estudos foucaultianos. 8. ed. Petrópolis: Vozes, 2011. p. 173 - 210.

REGO, Teresa Cristina (org.). Currículo e política educacional. Petrópolis, RJ: Vozes, 2011.

SAVIANI, Nereide. Saber escolar, currículo e didática: problemas da unidade conteúdo/método no processo pedagógico. 2 ed. Campinas, SP. Autores Associados, 1998. (Coleção educação contemporânea).

TYLER, Ralph Winfred. Princípios básicos de currículo e ensino. Tradução de Leonel Vallandro. Porto Alegre: Globo, 1977.

TRIVIÑOS, Augusto Nibaldo Silva. Introdução à pesquisa em ciências sociais: a pesquisa qualitativa em educação. São Paulo: Atlas, 1987. 


\section{ORGANIZAÇÃO CURRICULAR NA EDUCAÇÃO INFANTIL: UMA QUESTÃO DE GESTÃO ESCOLAR} RESUMO

O artigo tem o propósito de discorrer sobre a compreensão dos professores e coordenadores pedagógicos em relação ao processo de organização curricular da Educação Infantil. É uma pesquisa Qualitativa, fazendo uso de procedimentos metodológicos com aproximações de Estudo de Caso. A Educação Infantil é uma fase importante para o desenvolvimento da criança, e corroborando com estudos anteriores a presente pesquisa nos mostra que falta à maioria dos professores conhecimentos específicos acerca da organização curricular para a Educação Infantil, além do desconhecimento sobre documentos e leis que amparam sua profissão, contudo se faz necessário criar possibilidades de aprendizagens tanto para os profissionais da educação quanto aos alunos.

Palavras-chaves: Gestão Democrática; Organização Curricular; Educação Infantil; Escola Privada.

\section{CURRICULAR ORGANIZATION IN CHILD EDUCATION: A QUESTION OF SCHOOL MANAGEMENTABSTRACT}

The paper is intended to discuss the understanding of teachers and coordinators in relation to the process of curricular organization of early childhood education. This is Qualitative research, making use of methodological procedures approximations Case Study. It is noteworthy that early childhood education is an important phase in the development of the child, and corroborating previous studies in this research show that most teachers lack specific knowledge about the organization of the curriculum for Early Childhood Education, as well as lack of knowledge about documents and laws that support your profession, however it is necessary to create learning opportunities for both professional education as students.

Keywords: Democratic Management; Curriculum Organization; Early Childhood Education; Private School.

\section{ORGANIZACIÓN CURRICULAR EN LA EDUCACIÓN INFANTIL: UNA CUESTIÓN DE GESTIÓN ESCOLAR} RESUMEN

El artículo tiene el propósito de discurrir sobre la comprensión de los profesores y coordinadores pedagógicos en relación al proceso de organización curricular de la Educación Infantil. Es una investigación Cualitativa, haciendo uso de procedimientos metodológicos con aproximaciones de Estudio de Caso. La Educación Infantil es una fase importante para el desarrollo del niño, y corroborando con estudios anteriores la presente investigación nos muestra que falta a la mayoría de los profesores conocimientos específicos acerca de la organización curricular para la Educación Infantil, además del desconocimiento sobre documentos y leyes que amparan profesión, sin embargo se hace necesario crear posibilidades de aprendizaje tanto para los profesionales de la educación y los alumnos.

Palabras claves: Gestión Democrática; Organización Curricular; Educación Infantil; Escuela Privada. 